\title{
Tuberculosis status among patients visiting antiretroviral therapy centers of Seti Zonal Hospital and Mahakali Zonal Hospital of far western Nepal
}

\author{
Govinda Prasad Dhungana, ${ }^{*}$ Madan Singh Bohara, ${ }^{1}$ Sashi Sharma, ${ }^{2}$ Ananya Adhikari, ${ }^{3}$ Prem Khadga, ${ }^{2}$ \\ Basista Prasad Rijal, ${ }^{4}$ Bharat Mani Pokhrel, ${ }^{4}$ Bhawani Chand Thakuri, ${ }^{5}$ Krishna Prasad Pant ${ }^{1}$
}

\begin{abstract}
${ }^{1}$ Department of Microbiology Tribhuvan University Shree Siddhanath Science Campus, Mahendranagar, Kanchanpur, Nepal, ${ }^{2}$ Departmentof Medicine, Tribhuvan University Teaching Hospital, Kathmandu, Nepal, ${ }^{3}$ Medical officer, Meridian polyclinic, Maharajgunj, Kathmandu, Nepal, ${ }^{4}$ Department of Microbiology, Tribhuvan University Teaching Hospital, Kathmandu, Nepal, ${ }^{5}$ Farwestern University, Mahendranagr, Kanchanpur, Nepal
\end{abstract}

\author{
Accepted on \\ March 21, 2014 \\ DOI Name \\ http://dx.doi.org/10.3126/jaim.v3i1.10696 \\ Keywords \\ HIV; Tuberculosis; Far-western; Nepal \\ Citation \\ Govinda Prasad Dhungana, Madan Singh Bohara, \\ Sashi Sharma, Ananya Adhikari Prem Khadga, \\ Basista Prasad Rijal, Bharat Mani Pokhrel, Bhawani \\ Chand Thakuri, Krishna Prasad Pant Tuberculosis \\ status among patients visiting antiretroviral \\ therapy centers of Seti Zonal Hospital and Mahakali \\ Zonal Hospital of far western Nepal. Journal of \\ Advances in Internal Medicine 2014;03(01):11-16.
}

\begin{abstract}
Background and aims: Tuberculosis is still a major public health problem in Nepal. The situation is further worsened by the widespread epidemic of HIV. Knowledge of TB/HIV co-infection is essential for effective dual case management. The objective of this study was to determine the TB/HIV coinfection status among patients visiting antiretroviral therapy centers of Seti Zonal Hospital and Mahakali Zonal Hospital.
\end{abstract}

Methods: A cross sectional study was carried out in the department of Microbiology at Siddhanath Science Campus, Mahendranagar between January 2012 and July 2012. One hundred three patients were randomly selected, and were investigated for tuberculosis by direct microscopy and cultural technique. Socio-demographic features were collected by pre structured questionnaire. Data were entered into SPSS 11.5 and analyzed.

Results: Of the 103 people infected with HIV, 46 (44.7\%) were males and $57(55.3 \%)$ were females. Majority (64.07\%) of them were in the productive age group (21-40 years). Forty two (40.8\%) of the respondents were not literate. As high as $43.9 \%$ of the women were widow and $10.7 \%$ of the studied subjects showed mother to child transmission. The overall prevalence of TB among HIV infected people was found to be $4.9 \%$. Among five TB cases only two cases were detected by direct microscopy.

Conclusion: The overall prevalence of TB among HIV infected people was found to be $4.9 \%$. Youths of productive age groups with low socioeconomic status were more vulnerable to HIV/AIDS. Culture was found to be more superior method of diagnosis than microscopy.

\section{BACKGROUND}

Human immunodeficiency Virus (HIV) causes progressive impairment of the body's cellular immune system leading to increased susceptibility to tumors, and to the fatal condition known as Acquired Immunodeficiency Syndrome (AIDS). ${ }^{1}$ Due to lack of vaccines and/or effective therapies, the disease causes a lifelong disability not only to the individual, but also to the society as a whole. The Nepal's social economic status, prevailing norms and values, cultural myths on sex and sexualities and a huge population of marginalized communities make it extremely vulnerable to the HIV and/or sexually transmitted infections (STIs) epidemic. Furthermore, the high migration rate, more particularly as we see in hilly regions of western Nepal, is still a major factor for steep increases of AIDS epidemic in Nepal. ${ }^{2}$ Tuberculosis (TB) and

\footnotetext{
* Corresponding author Govinda Prasad Dhungana

Faculty member, Department of Microbiology

Tribhuvan University Shree Siddhanath Science Campus, Mahendranagar, Nepal. E-mail: dhunganagovinda7826@yahoo.com
} 
HIV have been closely linked since the emergence of AIDS. HIV infection has contributed to a significant increase in the worldwide incidence of tuberculosis. ${ }^{3}$ By deteriorating the cell-mediated immunity which play key role in eliminating the intracellular pathogen such as Mycobacterium tuberculosiss, HIV greatly increases the risk of developing active tuberculosis disease in co-infected individuals and leading to more frequent extrapulmonary involvement and atypical radiographic manifestations. Although HIV-related tuberculosis is both treatable and preventable, incidence rates continue to increase in resource limited developing countries where HIV infection and tuberculosis are endemic. Worldwide, M. tuberculosis is the most common opportunistic pathogen affecting HIVseropositive individuals, and active TB is the most common cause of death in patients with AIDS. ${ }^{4,5}$

In 2011, there were an estimated 1.1 million new HIV-positive TB cases globally. Around $79 \%$ of these people lived in subSaharan Africa. In 2011 an estimated 430,000 people died of HIV-associated TB. ${ }^{6}$ WHO report published in 2010 estimated that The South-East Asia Region accounts for nearly $15 \%$ of the global burden of new HIV-positive tuberculosis cases. ${ }^{7} \mathrm{~TB} / \mathrm{HIV}$ epidemiological studies carried out in certain urban areas of Nepal during the past few years showed that the prevalence rate of TB in HIV infected persons varied according to different regions. A Pokhara (western region) based study conducted in 2009 documented 5.97 \% TB in HIV/AIDS patients. ${ }^{8}$ Similar studies conducted in Kathmandu (central region) during nearly the same period documented $10.0 \%$ TB in HIV/AIDS patients. ${ }^{9}$ Tuberculosis was found to be the major opportunistic infection accounting $27.3 \%$ among HIV/AIDS patients admitted between December 2008 to May 2009 in Seti Zonal Hospital, Dhangadi (far western region). ${ }^{10}$

The far western region of Nepal has a relatively high burden of cases of HIV/AIDS in the country ${ }^{11}$. But an in-depth study, especially on the two urban areas of far west region (i.e Kailali and Kanchanpur districts), has not been done yet. Therefore, this study was conducted with a general objective of determining the situation of TB/HIV co-epidemic in this region.

\section{METHODS}

A cross sectional study was carried out in the Department of Microbiology, Siddhanath Science Campus, Mahendranagar, Kanchanpur, from January 2012 to July 2012. Sample size calculation was done using Cochrane formula, $n=z^{2} p q / d^{2}$, where $n=$ minimal sample size required, $p=$ prevalence of TB as documented in most recent study which was $5.97 \%(0.059)^{8}, q=1-p, Z=$ standard deviation usually set as 1.96 at $95 \%$ confidence interval, $d=$ degree of accuracy desired set as 0.05 . Therefore $=1.96^{2} \times 0.059 \times 0.941 / 0.05^{2}=85.31$. Thus, the sample size was calculated to be 85.31 , hence, at least 86 cases should be studied.

Altogether 103 People living with HIV/AIDS (PLWHA) volunteers (both symptomatic and asymptomatic) were included in the study. Sampling sites were the antiretroviral therapy centers of the two government hospitals of Kailali and Kanchanpur districts -- Seti Zonal Hospital, Dhangadi and Mahakali Zonal Hospital, Mahendranagar, respectively.

Patient selection was done by random sampling method using the list of patients available in the respective sites. As soon as HIV infected people were identified, an investigator was sent with the required number of wide mouthed, screw capped, leak proof, sterile sputum container. After taking informed consent, they were asked to fill up the prestructured questionnaire. The patients were then instructed to collect the sputum by deep coughing of an adequate amount of mucopurulent part - approximately $2 \mathrm{ml}$ - from the lower respiratory tract. Three separate specimens were collected (the first Spot specimen, early morning specimen, and second spot specimen). All the specimens were transported to the department of Microbiology Shree Siddhanath Science Campus, Mahendranagar and specimen processing was done as per standard Microbiological operating procedure. Investigation of TB was done by acid fast bacilli (AFB) culture by modified Petroff's method using Loweinstein Jensen medium, and direct microscopy of AFB stained smear by Ziehl Neelsen method as per WHO protocol. ${ }^{1,12}$ To eliminate wrong evaluation, quality control of the sputum was done for possible cases. If another sampling was possible, specimen without mucopurulent part was rejected and asked for another sample.

\section{RESULTS}

Of the 103 PLWHA, 46 (44.7\%) were male and 57 (55.3\%) were female. Sixty six of them were in the productive age group i.e. 21-40 years accounting $64.07 \%$. Childhood and elderly cases were very low as shown in the table. Forty two (40.8\%) of the respondents were illiterate and the rate of illiteracy was more in females than it was in males i.e. among the illiterate, thirty were females and twelve were males. This was followed by primary level education. Among forty respondents with primary level education, 19 were males and 21 were females. Respondents were found to be of low socio- economic status. Farmers and unemployed people were more than the other groups, accounting as high as $54.3 \%$ (combined) of the total population. This was followed by people involved in NGOs/ 
INGOs. Employed people were very few. Fifty six (54.4\%) respondents were married. $43.9 \%$ of women were widows. In contrast, only $4.3 \%$ of men were widow. Only one female was divorced. 82 (79.6\%) respondents had acquired HIV infection by sexual means, followed by mother to child transmission (10.7\%), Injecting drug users (8.7\%) and only one person had acquired HIV infection through blood. Majority (59.2\%) of the respondents were in the WHO II stage of HIV infection. 79 (76.7 \%) respondents were undergoing ART. Only 10 (9 9.7\%) respondents were alcohol consumers and only 20 (19.4\%) respondents were found to be regular smokers (table 1 ).

Table 1 Socio-demographic features of respondents

\begin{tabular}{|c|c|c|c|}
\hline Attributes & $\begin{array}{c}\text { Male } \\
\text { Number } \\
(\%)\end{array}$ & $\begin{array}{c}\text { Female } \\
\text { Number } \\
(\%)\end{array}$ & $\begin{array}{c}\text { Total } \\
\text { Number (\%) }\end{array}$ \\
\hline Age group (Yrs) 1-10 & $4(8.7)$ & $1(1.8)$ & $5(4.9)$ \\
\hline $11-20$ & $2(4.3)$ & $4(7.0)$ & $6(5.8)$ \\
\hline $21-30$ & $9(19.6)$ & $20(35.1)$ & $29(28.2)$ \\
\hline $31-40$ & $17(37.0)$ & $20(35.1)$ & $37(35.9)$ \\
\hline $41-50$ & $11(23.9)$ & $9(15.8)$ & $20(19.4)$ \\
\hline $51-60$ & $3(6.5)$ & $3(5.3)$ & $6(5.8)$ \\
\hline \multirow[t]{4}{*}{ Education } & $12(26.1)$ & $30(52.6)$ & $42(40.8)$ \\
\hline & $19(41.3)$ & $21(36.8)$ & $40(38.8)$ \\
\hline & $4(8.7)$ & $3(5.3)$ & $7(6.8)$ \\
\hline & $3(6.5)$ & 0 & $3(2.9)$ \\
\hline Bachelor & $1(2.2)$ & 0 & $1(1.0)$ \\
\hline Occupation Farming & $11(23.9)$ & $22(38.6)$ & $33(32.0)$ \\
\hline Unemployed & $13(28.3)$ & $10(18.0)$ & $23(22.0)$ \\
\hline I/ NGO & $6(13.0)$ & $7(12.3)$ & $13(12.6)$ \\
\hline Students & $5(10.9)$ & $6(10.5)$ & $11(10.7)$ \\
\hline Job & $4(8.7)$ & $6(10.5)$ & 10(9.7) \\
\hline Business & $6(13.0)$ & $3(5.3)$ & $9(8.7)$ \\
\hline Volunteer & $1(2.2)$ & $3(5.3)$ & $4(3.9)$ \\
\hline Marital status Married & $33(71.7)$ & $23(40.4)$ & $56(54.4)$ \\
\hline Widow & $2(4.3)$ & $25(43.9)$ & $27(26.2)$ \\
\hline Unmarried & 11(23.9) & $8(14.0)$ & 19(18.4) \\
\hline Divorced & 0 & $1(1.8)$ & $1(1.0)$ \\
\hline Mode of Infection Sexual & $30(65.2)$ & $52(91.2)$ & $82(79.6)$ \\
\hline Mother to child & $6(13.0)$ & $5(8.8)$ & $11(10.7)$ \\
\hline Injecting drug use & $9(19.6)$ & 0 & $9(8.7)$ \\
\hline Blood & $1(2.2)$ & 0 & $1(1.0)$ \\
\hline WHO staging Stage I & $15(32.6)$ & $11(19.3)$ & $26(25.2)$ \\
\hline Stage II & $22(47.8)$ & $39(68.4)$ & $61(59.2)$ \\
\hline Stage III & $8(17.4)$ & $6(10.5)$ & $14(13.6)$ \\
\hline Stage IV & $1(2.2)$ & $1(1.8)$ & $2(1.9)$ \\
\hline ART status & $39(84.8)$ & $40(70.2)$ & $79(76.7)$ \\
\hline No & $7(15.2)$ & $17(29.8)$ & $24(23.3)$ \\
\hline Alcoholic habit Yes & $9(19.6)$ & $1(1.8)$ & $10(9.7)$ \\
\hline No & $37(80.4)$ & $56(98.2)$ & $93(90.3)$ \\
\hline Smoking habit Yes & $16(34.8)$ & $4(7.0)$ & $20(19.4)$ \\
\hline No & $30(65.2)$ & $53(93.0)$ & $83(80.6)$ \\
\hline Total & $46(100)$ & $57(100)$ & $103(100)$ \\
\hline
\end{tabular}

Tuberculosis was detected in five people, giving an overall prevalence of $4.9 \%$. Among five co-infected cases, three were females and two were males. Two cases were in the age group of 21- 30 years; two cases were in the age group of 31-40 years and rest one case was in the age group of 41-50. All of them had CD4 count below 500. All five cases were detected by Acid Fast Bacilli (AFB) culture, of which only two cases were detected by direct microscopy of AFB stained sputum smear (table 2, 3, 4 and 5).

Table 2 Distribution of tuberculosis by gender

$\begin{array}{cccc}\begin{array}{c}\text { TB } \\ \text { status }\end{array} & \begin{array}{c}\text { Male } \\ \text { Number (\%) }\end{array} & \begin{array}{c}\text { Female } \\ \text { Number (\%) }\end{array} & \begin{array}{c}\text { Total } \\ \text { Number (\%) }\end{array} \\ \text { Yes } & 2(4.3) & 3(5.3) & 5(4.9) \\ \text { No } & 44(95.70 & 54(94.7) & 98(95.1) \\ \text { Total } & 46(100) & 57(100) & 103(100)\end{array}$

Table 3 Distribution of tuberculosis by Age group

$\begin{array}{cccc}\begin{array}{c}\text { Age group } \\ \text { (Yrs) }\end{array} & \begin{array}{c}\text { Yes } \\ \text { Number (\%) }\end{array} & \begin{array}{c}\text { No } \\ \text { Number (\%) }\end{array} & \begin{array}{c}\text { Total } \\ \text { Number (\%) }\end{array} \\ 1-10 & 0 & 5(5.1) & 5(4.9) \\ 11-20 & 0 & 6(6.1) & 6(5.8) \\ 21-30 & 2(40.0) & 27(27.6) & 29(28.9) \\ 31-40 & 2(40.0) & 35(35.7) & 37(35.9) \\ 41-50 & 1(20.0) & 19(19.4) & 20(19.4) \\ 51-60 & 0 & 6(6.1) & 6(5.8)\end{array}$

Table 4 Distribution of tuberculosis by CD4 count

\begin{tabular}{|c|c|c|c|}
\hline \multirow{2}{*}{$\begin{array}{l}\text { CD4 } \\
\text { count }\end{array}$} & \multicolumn{2}{|c|}{ TB status } & \multirow{2}{*}{$\begin{array}{c}\text { Total } \\
\text { Number (\%) }\end{array}$} \\
\hline & $\begin{array}{c}\text { Yes } \\
\text { Number (\%) }\end{array}$ & $\begin{array}{c}\text { No } \\
\text { Number (\%) }\end{array}$ & \\
\hline $1-200$ & $1(20.0)$ & $19(21.8)$ & $20(21.7)$ \\
\hline $201-500$ & $4(80.0)$ & $42(48.3)$ & $46(50.0)$ \\
\hline $501-1500$ & 0 & $26(29.9)$ & $26(28.3)$ \\
\hline Total & $5(100)$ & $87(100)$ & $92(100)$ \\
\hline
\end{tabular}

Table 5 Distribution of tuberculosis by modalities of diagnosis

$\begin{array}{cccc}\begin{array}{c}\text { Growth in LJ } \\ \text { medium } \\ \text { Yes }\end{array} & \text { AFB found } & \text { AFB not found } & \text { Total } \\ \text { No } & 2 & 3 & 5 \\ \text { Total } & 0 & 98 & 98 \\ & 2 & 101 & 103\end{array}$

Four of the TB/HIV co-infected persons were illiterate and the remaining one had attained primary education. Regarding occupation, two were Unemployed, two were farmers and one 
was student. All were undergoing ART, four were in the clinical stage II and only one was in clinical stage I (table 6)

Table 6 Distribution of tuberculosis by Educational status.

\begin{tabular}{|c|c|c|c|}
\hline \multirow{2}{*}{$\begin{array}{c}\text { Features } \\
\text { Educational } \\
\text { status }\end{array}$} & \multicolumn{2}{|c|}{ TB status } & \multirow{2}{*}{$\begin{array}{c}\text { Total } \\
\text { Number (\%) }\end{array}$} \\
\hline & $\begin{array}{c}\text { Yes } \\
\text { Number (\%) }\end{array}$ & $\begin{array}{c}\text { No } \\
\text { Number (\%) }\end{array}$ & \\
\hline Illiterate & $4(80.0)$ & $38(38.8)$ & $42(40.8)$ \\
\hline Primary & $1(20.0)$ & $39(39.8)$ & $40(38)$ \\
\hline Lower Sec. & 0 & $7(7.1)$ & $7(6.8)$ \\
\hline Secondary & 0 & $10(10.2)$ & 10(9.7) \\
\hline Higher Sec. & 0 & $3(3.1)$ & $3(2.9)$ \\
\hline Bachelor & 0 & $1(1.0)$ & $1(1.0)$ \\
\hline \multicolumn{4}{|l|}{ Occupation } \\
\hline Farming & $2(40.0)$ & $31(31.6)$ & $33(32.0)$ \\
\hline Unemployed & $2(40.0)$ & $21(21.4)$ & $23(22.3)$ \\
\hline I/NGO & 0 & $13(13.3)$ & $13(12.6)$ \\
\hline Student & $1(20.0)$ & $10(10.2)$ & $11(10.7)$ \\
\hline Job & 0 & $10(10.2)$ & 10(9.7) \\
\hline Business & 0 & $9(9.2)$ & $9(8.7)$ \\
\hline Volunteer & 0 & $4(4.1)$ & $4(3.9)$ \\
\hline \multicolumn{4}{|l|}{ WHO staging } \\
\hline Stage I & $1(20.0)$ & $25(25.5)$ & $26(25.2)$ \\
\hline Stage II & $4(80.0)$ & $57(58.2)$ & $61(59.2)$ \\
\hline Stage III & 0 & $14(14.3)$ & $14(13.6)$ \\
\hline Stage IV & 0 & $2(2.0)$ & $2(1.9)$ \\
\hline \multicolumn{4}{|l|}{ ART status } \\
\hline Yes & $5(100)$ & 75 (76.5) & $80(77.7)$ \\
\hline No & 0 & $23(23.5)$ & $23(22.3)$ \\
\hline Total & $5(100)$ & $98(100)$ & $103(100)$ \\
\hline
\end{tabular}

Regarding clinical sign and symptoms, cough, chest pain and loss of appetite were found to be the major sign and symptoms of TB/HIV co-infected persons followed by abdominal pain, headache and night sweats (table 7)

Table 7 Distribution of tuberculosis by sign and symptoms

\begin{tabular}{cccc}
\hline $\begin{array}{c}\text { Clinical } \\
\text { features }\end{array}$ & $\begin{array}{c}\text { Yes } \\
\text { Number } \\
(\%)\end{array}$ & $\begin{array}{c}\text { TB status } \\
\text { Number } \\
(\%)\end{array}$ & $\begin{array}{c}\text { Total } \\
\text { Number } \\
(\%)\end{array}$ \\
\hline Cough & $3(60.0)$ & $29(29.6)$ & $32(31.1)$ \\
Chest pain & $3(60.0)$ & $22(22.4)$ & $25(24.3)$ \\
Loss of appetite & $3(60.0)$ & $17(17.3)$ & $20(19.4)$ \\
Weight loss & $2(40.0)$ & $16(16.3)$ & $18(17.5)$ \\
Night sweat & $2(40.0)$ & $12(12.2)$ & $14(13.6)$
\end{tabular}

\section{DISCUSSION}

The socio- demographic characteristics of the patients demonstrated the relatively high proportion of females (55.3\%) attending ART sites in this region, as compared to the national situation. A similar study carried out during 2009 in ten ART sites across Nepal showed lower proportion of females (43\%) than males. ${ }^{13}$ Furthermore, table 1 reveals that as high as $43.9 \%$ of the female were widow and $10.7 \%$ constitutes the mother to child transmission of HIV. A Kathmandu based study conducted in 2008 showed that only $26.0 \%$ of female were widow and only $1.3 \%$ of childhood HIV cases. ${ }^{9}$ This scenario represents the general trend of the major socioeconomic problem that lead to the spread of HIV epidemic in the Far Western region of Nepal suggesting that the HIV epidemic in the Far Western region is on the verge of attaining generalized form, affecting the silent population such as women (housewives) and children, and the migrant labors were acting as the carriers of the virus. A previous socio-demographic study of PLWHA visiting Seti Zonal hospital ART center suggested that most of the people of this region were traveling to India to earn money as migrant laborers. There they acquired HIV infection and transmitted the infection to their innocent housewives during their short visit to home ${ }^{2}$. The findings of our study also support this fact as the majority of the HIV infected patients were in the productive age group, i.e 31-40 years, illiterate and were unemployed. All these factors in association with unsafe sexual practices were found to be the major cause of HIV transmission. The age wise distribution of studied population is consistent with those of other socio-demographic studies conducted in different parts of the nation. ${ }^{9,10,14}$ High burden of HIV in this age group may be due to the fact that early adolescent age is considered to be the age of freedom, adolescents are sexually active and are more inclined towards vulnerable activities.

This study documents the $4.9 \%$ prevalence of tuberculosis among HIV infected persons in Kailali and Kanchanpur districts. A Similar study conducted in Kathmandu (central region) during nearly the same period documented $10 \%$ TB in HIV/ AIDS patients. ${ }^{9}$ Another study carried out in Pokhara in 2009 documented $5.97 \%$ TB in HIV/AIDS patients. ${ }^{8} \quad$ More recent studies carried out in admitted HIV/AIDS patients in Seti Zonal Hospital, Dhangadi documented $27.3 \%$ TB prevalence. ${ }^{10}$ These variations in prevalence rate of TB among the HIV patients are presumed to result from different geographic, climatic and socioeconomic condition. Furthermore, In a TB surveillance among HIV infected persons in Cambodia, it was observed that $9 \%$ of the participants were positive for TB. ${ }^{15}$ In general it was observed that various clinical manifestations such as cough, chest pain, weight loss, loss of appetite etc were 
more common in TB co-infected HIV patients in comparison to non co-infected counterparts. Similarly, higher percentage of TB cases were seen in patients with low CD4 count $(<500)$. These clinical and laboratory markers could be useful for surveillance of TB/HIV co-infection. Microbiologically, the most important findings of this study was the exploration of the fact that TB case detection by cultural technique was found to be the most effective (which detected all five cases of TB) than direct observation of AFB stained smear (which detected only two cases of TB) i.e. there was a predominance of smear negative TB cases among people infected with HIV. Therefore, on the basis of this study, it can be recommended that the TB control organizations should take concrete steps regarding the inclusion of cultural techniques along with direct microscopy, at least for HIV infected people. Furthermore, Socioeconomic profile of the patients suggested that youths of productive age groups with low socioeconomic status were more vulnerable to get infected with HIV/AIDS. So, special program targeted on this marginalized communities should be launched to create public awareness through behavior change communication/ Information education communication.

One of the most important limitations of this study is that this study could not reflect the scenario of TB/HIV burden in the community level because the sampling sites were antiretroviral therapy centers of Seti Zonal Hospital and Mahakali Zonal Hospitals of far western Nepal. In fact, more extensive community based surveillance is recommended to

\section{REFERENCES}

1. Cheesbrough M. District Laboratory Practice in Tropical countries. Cambridge University Press, 2002;2:71-211.

2. Paudel BN, Sharma S, Singh GB, et al. Socio-demographic profile of HIV patients at Seti Zonal Hospital. J Nepal Health Res Counc, 2008;6(13):107-10.

3. Raviglione MC, Narain JP, Kochi A. HIV-associated tuberculosis in developing countries: clinical features, diagnosis, and treatment. Bull WHO. [Internet].1992;70:515-526.

4. Sharma SK, Mohan A, Kadhiravum T. HIV/TB Coinfection: epidemiology, diagnosis and management, Indian Journal of Medical Research 2005;121:550-567.

5. World Health Organization. Tuberculosis hand book, 1998, WHO, Geneva.

6. World Health Organization. TB/HIV factsheet. Available get the more representative data of the TB/ HIV co-infection to develop national policy regarding this burning issue.

\section{CONCLUSION}

In HIV/AIDS patients, the overall prevalence of TB was found to be $4.9 \%$. The disease is predominantly affecting youths of productive age groups with low socioeconomic status. Cultural technique was found to be more effective in detecting higher cases of TB in these groups of people. In general it was observed that various clinical manifestations such as cough, chest pain, weight loss, loss of appetite etc were more common in TB co-infected HIV patients in compared to non coinfected counterparts. Similarly, higher percentage of TB cases were seen in patients with low CD4 count $(<500)$.

\section{ACKNOWLEDGEMENT}

Authors would like to express sincere thanks to University Grants Commission for approving the faculty research grants without of which this study could not have been initiated. We are also equally thankful to Dr. Purna Bahadur Chand, Campus chief, Shree Siddhanath Science campus for permitting us to use the microbiology lab. Personally, we would like to thank Mr. Bhanu Paneru, M.Sc student for his technical assistant, and Bhagirth Joshi (Lab boy) for his kind cooperation during the study period. Finally, we are also thankful to all the HIV/ AIDS related organizations as well as PLWHA volunteers who participated in this study.

from:http://www.who.int/tb/challenges/hiv/tbhiv_ factsheet_2013.pdf.

7. World Health Organization. HIV/AIDS in the South East Asia region. Progress report 2010. Available from: http://aidsdatahub.org/dmdocuments/WHO_2010_ HIV_AIDS_in_ the_South_East_Asia_Region_Progress_ Report_2010.pdf,

8. Verma SC, Dhungana GP, Joshi HS, et al. Prevalence of pulmonary tuberculosis among HIV infected persons in Pokhara, Nepal. J Nepal Health Res Counc. 2012;10:32-6.

9. Sharma S, Dhungana GP, Pokhrel BM, et al. Opportunistic infections in relation to CD4 level among HIV seropositive patientsfromcentral Nepal. Nepal Med CollJ.2010;12:1-4.

10. Poudel BN, Dhungana GP. Scenario of HIV/AIDS patients in a government hospital of Nepal. J Nepal Health Res Counc. 2010;8:103-6. 
11. Suvedi BK. Transition of HIV epidemic in Nepal. Kathmandu Univ Med J (KUMJ). 2006;4:115-8.

12. World Health Organization. Laboratory service in tuberculosis control, tuberculosis culture, WHO, 1998, Geneva.

13. Wasti SP, Simkhada P, Randall J, et al. Factors Influencing Adherence to Antiretroviral Treatment in Nepal: A Mixed-Methods Study. PLoS One 2012; 7(5):e35547.
14. Ghimire P, Dhungana JR, Bam DS, et al. Tuberculosis and HIV co-infection status in United mission Hospital, Tansen. SAARC j Tuberc Lung Dis HIV/AIDS, 2004;1:32-7.

15. Kimberling ME, Schuchter J, Chanthol E, et al. Prevalence of pulmonary tuberculosis among HIV-infected persons in a home care program in Phnom Penh, Cambodia. Int J Tuberc Lung Dis 2002;6:988-94.

http://dx.doi.org/10.1371/journal.pone.0035547 